\title{
大都市城乡融合区空间演进及内在关联性测度 基于武汉市夜间灯光数据
}

\author{
吴 燕, 李红波* \\ (华中农业大学公共管理学院,武汉 430070)
}

\begin{abstract}
摘 要: 大都市城乡融合区时空演变及其内在空间关联性研究对避免城市低效蔓延式发展、实现空间结构协同和精 明增长有重大意义。论文以武汉市城乡融合区为研究对象, 基于 NPP/VIIRS 夜间灯光强度表征都市要素配置及运 行效率和效益, 利用引力模型测度 2016-2018年各城乡融合区空间关联强度, 分析各城乡融合区空间联系势能时 空演变趋势和社会经济区位度变化。研究结果表明: (1) 武汉市城乡融合区面积在 2016-2018 年间扩大了 $28.10 \%$, 小斑块区域逐渐整合, 区域发展连续性增强, 总体向西北方向扩展最为显著; 2 武汉市城乡融合区之间的空间联 系网络结构整体上趋向 “多中心”分布,这一过程源于各城乡融合区的经济发展水平、城镇化发展规模和交通通达 性变化,东湖新技术开发区、中法武汉生态示范城、武汉临空经济区等在此过程中是各城乡融合区的区域发展引 擎; (3) 武汉市城乡融合区空间联系强度整体上逐年上升, 空间联系整体格局从武洪区和江夏区的“大小中心”结构 过渡到江夏区一武洪区一蔡汉区一江黄区一江研东区的“外围圈层式”结构,但洪山区和江夏区作为武汉市城乡融 合区中心区域, 未能形成多方向空间辐射力和吸引力, 对其他地区的带动明显不足; (4) 各城乡融合区社会经济区 位度变化显示, 现行武汉市都市发展区规划实施成效在北部、西部和东北部城乡融合区较为显著。
\end{abstract}

关 键 词: 空间关联; 引力模型; NPP/VIIRS 夜间灯光; 城乡融合区; 武汉市

中国许多特大城市和超大城市城镇扩张面积 与新增城镇化人口比例已超过国际 $1: 1.2$ 的合理水 平, 城市低效无序扩张成为困扰新型城镇化发展的 首要基本问题。对此,国家和政府多次强调城市可 持续化集约发展, 提出以人为本的高质量新型城镇 化发展道路, 在追求城市规模扩张的同时更加注重 城市的综合能力提升, 以生态、高效、集约的方式实 现城市精明增长 ${ }^{[1]}$, 全面提升城市的承载力、集聚力 和竞争力。城镇化高速发展和城市空间快速扩张 (扩展)或曼延, 形成了一种具备一定人口密度和城 市服务功能、城乡土地利用混杂交错、社会经济结 构急剧变化、城市向乡村的过渡带, 即城乡融合区, 作为城市功能和空间扩展的前沿, 兼有城市与乡村
的双重特征。近 $30 \mathrm{a}$ 城镇化过程中, 城乡融合区受 城市圈层式扩张力和城市内聚力的共同影响 ${ }^{[2]}$, 其 建设用地空间扩展在各方向上呈现圈层式的“城市 年轮” ${ }^{[3-4]}$ 。在这种城镇化高速发展表象下, 城乡融 合区内部发展并不均衡,在经济、人口和空间等方 面存在较大差异, 突出表现在发展程度不均衡、核 心区辐射能力不足等, 这一系列问题直接影响城市 长期健康稳定发展。同时,城乡融合区处于城市圈 层式扩张力和城市内聚力的交汇区, 借助城市圈层 式扩张力推动城市信息、技术、物资等要素向边缘 流动, 实现了城市扩张; 利用城市域内网络促进要 素在城市内的循环流动与再生形成城市内聚力, 通 过区域间的相互吸引力反作用于城市圈层式扩张

收稿日期: 2019-02-25; 修订日期: 2019-06-06。

基金项目: 国家自然科学基金资助项目(41871179); 中央高校基本科研业务费专项资金资助项目(2662018YJ006)。[Foundation: National Natural Science Foundation of China, No. 41871179; Fundamental Research Funds for the Central Universities, No. 2662018YJ006. ]

第一作者简介: 吴燕(1996-), 女,湖北孝感人,硕士生,主要研究方向为土地资源管理与空间规划。E-mail: 1975419159@qq.com *通信作者简介: 李红波(1972-), 男, 湖北应城人,博士, 教授, 主要研究方向为土地资源管理与空间规划。

E-mail: lihb20132013@163.com

引用格式: 吴燕, 李红波. 大都市城乡融合区空间演进及内在关联性测度: 基于武汉市夜间灯光数据 [J]. 地理科学进展, 2020, 39(1): 13-23. [Wu Yan, Li Hongbo. Spatial change and correlations of desakota regions in a metropolitan area using NPP/VIIRS nighttime light data: A case study of Wuhan City. Progress in Geography, 2020, 39(1): 13-23. ] DOI: 10.18306/dlkxjz.2020.01.002 
过程, 城市内聚力和圈层式扩张力共同作用, 在很 大程度上影响城市扩展方向及速度。因此, 各城乡 融合区间的内在联系能够促进各经济社会要素在 空间上的集聚扩散,对城市空间功能、结构、发展方 向和速度具有直接影响。相关研究集中于城市蔓 延的空间特征和影响机制 ${ }^{\left[{ }^{[}\right]}$、城市扩张的监测与分 析 $^{[0]}$ 和驱动力 ${ }^{[7]}$, 较多关注于城市外围圈层扩张及其 动力, 却轻视了城市域内城乡融合区空间网络关联 及内聚力。空间联系作为网络化内聚力的形成基 础, 是协调区域内部竞争关系、探索区域一体化和高 质量发展的基本条件。国内外学者在空间关联研究 理论体系、模型构建及应用方面的成果较为丰厚, 其 中借助引力模型得到学者们的偏好。引力模型是物 理学应用于社会科学领域的经典模型 ${ }^{[8]}$, 经后来学 者不断改进, 相关应用扩展至经济贸易 ${ }^{[9]}$ 、可再生能 源的行业竞争 ${ }^{[10]}$ 、城市等级与空间结构演变 ${ }^{[8]}$ 、教育 公平 ${ }^{[11]}$ 和人口流动 ${ }^{[10]}$ 等多方面。在具体应用上, 城 市流模型、人口流动模型、信息流模型和交通流模型 可用于判断城市圈中心城市对其他各城市的辐射程 度, 潜力模型可用于判断各城市的集聚能力 ${ }^{[2]}$; 根据 空间相互作用的基本要素, 可从多角度分析城市群 内各城市的内在空间相互作用和对外辐射能力 ${ }^{[13]}$; 复杂社会网络分析和比较分析法可进一步分析基 于城镇间相互引力所构建的城镇联系网络, 从点、 线、网多层面剖析网络特征 ${ }^{[14]}$ 。显然, 空间关联的 已有研究主要针对城市之间的空间联系, 对城市内 部各空间之间的网络关联研究甚少。

以往利用引力模型测度区域间的空间关联, 常 以人口和 GDP 表示城市综合质量 ${ }^{[15]}$, 城乡融合区是 一个地域概念, 更是一个动态关系概念 ${ }^{[16]}$, 以行政 边界、环城公路、经济、人口等作区域划分依据难以保 证数据的时效性和准确性, 利用统计数据测算城乡 融合区的经济发展水平也难以确保研究范围的统 一性, 而新兴遥感技术获取的影像数据能够打破行 政边界, 突破统计口径限制, 实时反映城市的发展 状态 ${ }^{[17]}$ 。同时, 夜光遥感数据在反映经济增长 ${ }^{[18]}$ 、人 类活动 ${ }^{[19]}$ 、城镇化水平 ${ }^{[20]}$ 、贫困指数 ${ }^{[21]}$ 和能源消费 ${ }^{[22]}$ 等方面具有特殊能力, 能够实时反映城市要素配置 及运行效率和效益, 且通过卫星传感器扫描获取, 摆脱对体制与人力的依赖, 具有较强客观性、可比 性与易获取性 ${ }^{[23]}$ 。

本文以武汉市为案例, 利用 NPP(National Polar-Orbiting Partnership)/VIIRS(Visible Infrared Imaging Radiometer Suite)夜间遥感影像的灯光强度和起
伏度提取城市内城乡融合区的内外边界, 根据灯光 强度总和衡量各城乡融合区发展质量, 通过引力模 型测度各城乡融合区之间的空间联系强度, 分析各 城乡融合区空间联系势能时空演变趋势和社会经 济区位度变化率, 力求回答以下 3 个关键问题:第 一, 影响城市扩张方向及速度的城乡融合区空间相 互引力是如何分布的; 第二,各城乡融合区间空间 非均衡发展程度如何变化; 第三, 基于空间引力分 布, 量化城乡融合区社会经济区位度变化, 检验现 行城市规划实施中期成效。

\section{1 数据与方法}

\section{1 研究区概况与数据来源}

武汉市包括江岸区、江汉区、硚口区、汉阳区、 武昌区、洪山区、青山区、新洲区、黄陂区、东西湖区、 蔡甸区、汉南区和江夏区 13 个行政区, 是湖北省省 会城市和武汉城市圈的中心城市, 位于湖北省东部、 长江与汉水交汇处, 是全国重要的工业基地、科教 基地和综合交通枢纽。辖区面积约 $8569 \mathrm{~km}^{2}, 2017$ 年末户籍人口 853.65 万人, 常住人口达 1089.29 万 人, 全市人均 GDP 达到 123831 元, 城镇常住居民人 均可支配收人达 43405 元, 农村常住居民人均纯收 人达 20887 元。2017年武汉市江岸、江汉、研口、汉 阳、武昌、青山区常住人口城镇化率达 $100.00 \%$, 洪 山区 $96.75 \%$, 东西湖区 $65.28 \%$, 汉南区 $59.97 \%$, 蔡 甸区 $38.03 \%$, 江夏区 $53.71 \%$, 新洲区 $52.23 \%$, 黄陂 区 $46.64 \%$, 全市呈单中心、辐射式发展, 各区发展效 率差异明显 ${ }^{[24]}$ 。根据城镇化发展的 4 个阶段, 即城 镇化水平小于 $30 \%$ 为起步阶段、30\% 60\%之间为中 期阶段、60\% $80 \%$ 为后期阶段、 $80 \% \sim 100 \%$ 为终期 阶段 ${ }^{[25]}$,武汉市城镇化发展已步人后期阶段, 将迈人 终期成熟化阶段,需要转变城市发展方式, 严控盲目 扩张, 走资源节约、环境友好、集约紧凑的新型城镇 化道路, 强化城市内聚力网络的形成非常必要。

本文以美国国家海洋中心气象局提供的 NPP/ VIIRS 月合成夜间灯光遥感影像为基础数据, 辅以 武汉市行政边界数据、城市道路交通数据、高清谷 歌影像和土地利用分类数据。行政边界数据来源 于湖北省测绘地理信息中心; 道路交通数据来源于 2017 年 OpenStreetMap 的道路数据, 包括市一级和 二级道路数据; 土地利用分类数据来源于地理空间 数据云(http://www.gscloud.cn/)2015 年 Landsat 8 遥 感影像; 其他经济、人口数据来源于武汉市统计局 
官网和《武汉统计年鉴》。VIIRS 传感器相比 DMSP (Defense Meteorological Satellite Program)传感器不 存在光溢出效应 ${ }^{[26]}$, 且具有更高的空间分辨率 ${ }^{[27]}$ 、更 低的光成像检测 ${ }^{[28]} 、$ 更精细的量化 ${ }^{[27]}$ 和飞行校准 ${ }^{[29]}$, 有利于更好地表征城市要素配置及运行效率和效 益 ${ }^{[30]}$ 。2015-2017 年正值“十二五”规划末、“十三 五”规划初期, 为研究在“十二五”规划成果的基础 上“十三五”规划的成效,本文选取 2016、2017、2018 年每年 3 月的月合成夜间灯光遥感影像进行研究， 灯光亮度 $0 \sim 372$, 像元大小 $431.68 \mathrm{~m}^{2}$ 。运用 ArcGIS 10.2 软件按武汉市行政边界矢量数据提取夜间灯 光影像数据, 转为高斯克吕格投影坐标并将栅格大 小重采样为 $500 \mathrm{~m}$ 进行研究。

\section{2 城乡融合区提取}

城乡融合区位于集中连片的高人口密度区与 低密度农业人口、绿色自然景观连绵的农业生产活 动区域之间, 作为城镇化发展的特殊区域, 其样态 过渡性和格局动态性特征明显 ${ }^{[3]}$, 发展可塑性较 强。已有学者采用不透水面盖度与景观紊乱度 ${ }^{[32]}$ 、建 设用地比率 ${ }^{[3]} 、$ 二三产业人口增加值与人口密度 ${ }^{[34]}$ 等指标进行城乡空间边界识别。由于城市居民的 生活方式对灯光亮度的依赖程度远高于乡村,城乡 融合区的夜间灯光强度和起伏度具有从城市向乡 村过渡的特征 ${ }^{[17]}$, 也有学者利用 DMSP/OLS 夜间灯 光遥感数据的灯光亮度和起伏度组合值作为城乡 边缘的识别依据 ${ }^{[17,35]}$ 。NPP/VIIRS 夜光遥感数据具 有更高精度、不存在灯光溢出效应, 且均来自于 NPP 卫星的 VIIRS 传感器, 在较精细展现地区对灯光依 赖程度的同时, 避免了获取长时间序列灯光数据集 时不同传感器导致的灯光影像不连续问题 ${ }^{[3]}$ 。本 文利用夜间灯光强度提取城乡融合区内边界、夜间 灯光起伏度提取城乡融合区外边界, 灯光起伏度计 算公式如下:

$$
\mathrm{DN}_{w}=\mathrm{DN}_{\text {max }}-\mathrm{DN}_{\text {min }}
$$

式中: $\mathrm{DN}_{w}$ 指夜间灯光起伏度, $\mathrm{DN}_{\text {max }}$ 和 $\mathrm{DN}_{\text {min }}$ 分别指 夜间灯光 DN 的 $3 \times 3$ 邻域范围内的最大值和最小 值。由于武汉市内湖泊河流众多, 水域总体面积超 过市域面积达 $26 \%$, 在夜间灯光起伏度数据中, 湖 泊周围及内部出现大量异常值, 因此剔除水域范围 内异常值对灯光起伏度阈值选择的影响。此方法 基于以下 3 个假设: (1) 区域灯光强度越高, 其为城 市中心的可能性越大; (2) 在灯光图像中, 城市多边 形(斑块)随阈值增加而逐渐缩小, 当阈值逐渐缩小
到某一特殊值时, 玟块从内部出现破碎 ${ }^{[37]}$; (3) 城乡 融合区有别于市中心和乡村的均一性, 呈现过渡、 多样性特征 ${ }^{[17]}$, 其灯光亮度起伏度不同于市中心与 乡村。在 3 个基本假设的基础上,本文利用《武汉市 城市总体规划》和高清谷歌影像不断校正灯光國 值, 当灯光强度阈值取 25 , 灯光起伏度阈值取 5 时, 所提取的城乡融合区与城市规划和高清谷歌影像 拟合度最高。因此本研究中以灯光强度小于阈值 25 、灯光起伏度大于阈值 5 的区域作为城乡融合区 (图 1、图2)。

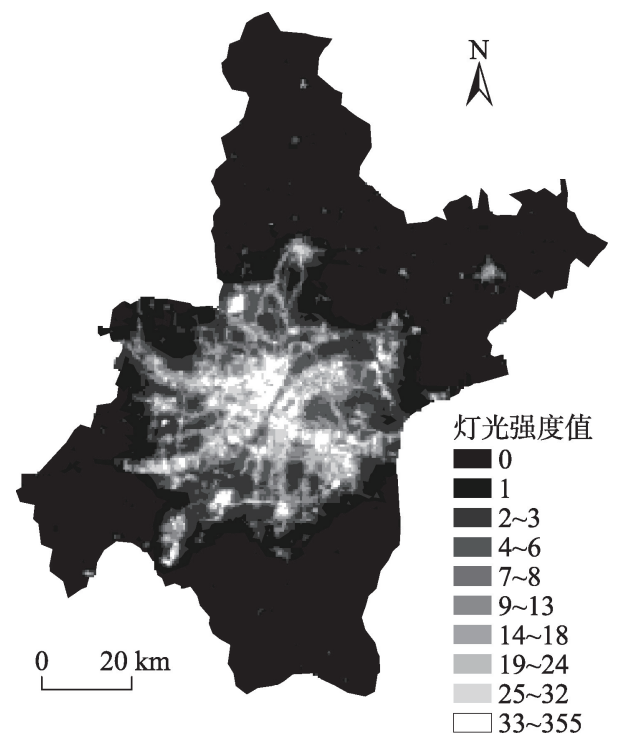

图 12018 年武汉市 NPP/VIIRS 夜间灯光强度

Fig.1 National Polar-Orbiting Partnership / Visible Infrared Imaging Radiometer Suite (NPP/VIIRS) nighttime

light data of Wuhan City, 2018

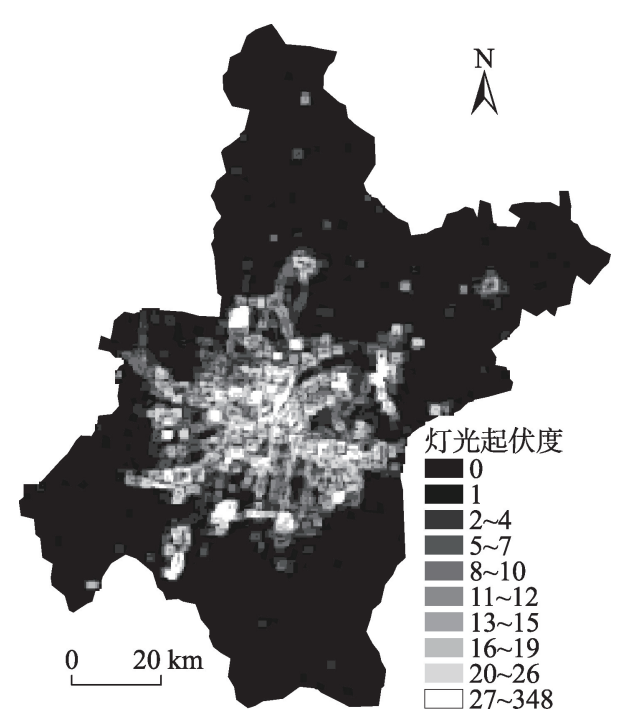

图 22018 年武汉市 NPP/VIIRS 夜间灯光起伏度

Fig.2 Fluctuation degree of light intensity of Wuhan City, 2018 


\section{3 城乡融合区空间关联测度}

引力模型基于距离衰减原理, 以物理学的万有 引力定律为基础, 广泛应用于空间联系研究, 其一 般表达式为 ${ }^{[38]}$ :

$$
G_{i j}=K \frac{Q_{i} Q_{j}}{l_{i j}^{r}}
$$

式中: $G_{i j}$ 为区域 $i$ 与区域 $j$ 的相互引力; $K$ 为引力常 数, 取值为 $1 ; Q_{i}$ 和 $Q_{j}$ 分别为区域 $i$ 和区域 $j$ 的质量 $; l_{i j}$ 为两区域之间的距离; $r$ 为距离摩擦系数, 即引力作 用范围的尺度差异, 主要受信息网络、交通运输线 网的密度和质量以及区域范围内交通方式的组成 和比例影响 ${ }^{[39]}$ 。根据张荆荆 ${ }^{[40]}$ 对 $r$ 的界定, 两邻接地 区间具有可通行高速公路或国道时 $r$ 值取 2.25 , 否 则取 2.5 ; 两非邻接地区间具有可通行高速公路或 国道时 $r$ 值取 2.75 , 否则取 3 , 考虑到武汉市城乡融 合区空间尺度较小, 且具有可通行一级、二级公路, 参考山西省县域中心村空间相互作用 ${ }^{[4]}$ 、江苏省县 市经济联系 ${ }^{[42]}$ 的取值, 最终确定本文引力模型中距 离摩擦系数取 2 。传统空间相互作用模型常以人口 和 GDP 表示城市综合质量 ${ }^{[15]}$, 对城市科技、文化、信 息等发展现状的特征描述存在一定的局限性。夜 间灯光强度能够综合体现城市经济、人口等活跃程 度 ${ }^{[43]}$, 表征城市城镇化水平 ${ }^{[20]}$, 因此本文以各城乡融 合区灯光强度值总和表征区域质量。

区域距离表示区域之间产生相互联系的倾向 度, 仅用空间直线距离难以表征该距离本质 ${ }^{[44]}$, 忽 略了交通便利度和节点本身经济规模的吸引力 ${ }^{[15]}$ 。 公路为城市内的主要交通出行方式, 因此选择武汉 市一级、二级公路的密度和设计速度作为交通便利 度影响因子。如式(3) 式(6), 本文采用交通便利度 系数和经济吸引力系数对基本引力模型进行修正, 并以江夏区和武昌、洪山区城乡融合区的空间关联 程度为标准值 100 , 测算武汉市各城乡融合区间的 空间关联强度。根据武汉市行政区划, 将城乡融合 区分为汉阳区, 青山区, 江夏区, 新洲区, 江汉、硚 口、东西湖区(后文简称江研东区), 武昌、洪山区(后 文简称武洪区), 蔡甸、汉南区(后文简称蔡汉区), 江 岸、黄陂区(后文称江黄区) 8 个部分。

$$
\begin{gathered}
T_{i j}=\frac{\left(R_{i}+R_{j}\right) / 2}{\sum_{i=1}^{n} R_{i} / n} \\
R_{i}=\frac{R_{i 1} \times V_{1}+R_{i 2} \times V_{2}}{V_{1}+V_{2}}
\end{gathered}
$$

$$
\begin{gathered}
E_{i j}=\frac{\left(M_{i}+M_{j}\right) / 2}{\sum_{i=1}^{n} M_{i} / n} \\
F_{i j}=T_{i j} E_{i j} \frac{M_{i} M_{j}}{d_{i j}^{2}}
\end{gathered}
$$

式中: $T_{i j}$ 为交通便利度系数; $R_{i} 、 R_{i}$ 分别为城乡融合 区 $i, j$ 的道路密度; $R_{i 1}$ 和 $R_{i 2}$ 分别为城乡融合区一、二 级道路密度, 由各城乡融合区内道路长度除以面积 得到; $V_{1}$ 和 $V_{2}$ 分别是城市一、二级公路的设计速度, 根据武汉市实际情况, 分别取 $80 \mathrm{~km} / \mathrm{h} 、 60 \mathrm{~km} / \mathrm{h} ; E_{i j}$ 为经济吸引力系数; $M_{i} 、 M_{i}$ 分别为城乡融合区 $i, j$ 的 质量; $F_{i j}$ 为城乡融合区 $i$ 和 $j$ 之间的空间联系强度; $d_{i j}$ 为城乡融合区 $i$ 和 $j$ 区域重心的距离。

区域之间的相互关联强度对城市经济、政治、 社会、文化等区位优劣势具有重大影响 ${ }^{[4]}$, 而夜间 灯光数据能够综合体现各区域经济、社会、文化等 发展状况,因此本文所求的各城乡融合区空间联系 强度可定义各区域的空间联系势能和社会经济区 位度,计算公式如下:

$$
\begin{gathered}
S_{i}=\sum_{j=1}^{n} F_{i j} \\
L_{i}=\frac{S_{i}}{\sum_{i=1}^{n} \sum_{j=1}^{n} F_{i j}}
\end{gathered}
$$

式中: $S_{i}$ 为城乡融合区 $i$ 的空间联系势能; $L_{i}$ 为城乡 融合区 $i$ 的社会经济区位度。

\section{2 结果分析}

\section{1 武汉市城乡融合区空间演变}

基于夜间灯光数据提取的城乡融合区具备一定 的人口密度和城市服务功能, 其边界推移代表城市 服务能力和效益发挥范围变化。分析提取结果发 现，2016-2018 年武汉市城乡融合区面积扩大 $28.10 \%$, 扩展速度达 $143.64 \mathrm{~km}^{2} / \mathrm{a}$ ，小玟块区域进一 步整合, 区域发展连续性增强。城乡融合区在各个 方向均有不同程度的扩张, 但总体向西北方向扩展 最为显著; 市中心规模扩大 $48.76 \%$, 扩展速度为 $77.28 \mathrm{~km}^{2} / \mathrm{a}$, 整体发展重心向东南方向偏移(图 3)。 江黄区、蔡汉区和新洲区城乡融合区外边界向外推 进幅度较大, 2 a 间面积分别扩大 $74.31 \%$ 、67.96\% 和 $56.75 \%$ 。城乡融合区向外扩张是乡村建设成效的 重要体现, 说明乡村基础设施和居民生活方式有所 改善。青山区、汉阳区和武洪区在2016-2018年间 
城乡融合区面积分别减小 $37.41 \% 、 31.8 \%$ 和 $21.14 \%$, 因其城镇化效果明显, 部分地区发展程度已升级至 市中心城镇化水平,致使城乡融合区呈收缩趋势。

2017 年武汉市常住人口、房地产开发投资额、 人均可支配收人和人均消费支出相比 2016 年分别 增加了 $1.2 \% 、 6.7 \% 、 6.2 \%$ 和 $7.6 \%$, 表明武汉市中心 和城乡融合区的扩张伴随着人口、经济和生活质量 等各方面的提升, 在一定程度上实现了城市精明增 长。如表 1 所示, 在人口紧凑性方面, 江研东区常住 人口增加 $4.0 \%$, 江黄区、江夏区、蔡汉区紧随其后, 常住人口分别增加 $2.2 \% 、 2.1 \%$ 和 $2.1 \%$, 对比各城乡 融合区面积扩展程度, 江研东区人口紧凑度较高。 在经济紧凑性方面,江夏区第二、三产业分别增加 $12.2 \%$ 和 $9.4 \%$, 人均可支配收人和支出分别增加 $9.6 \%$ 和 $2.1 \%$; 蔡汉区第二、三产业分别增加 $8.0 \%$ 和 $9.6 \%$, 人均可支配收人和支出分别增加 $10.2 \%$ 和 $2.1 \%$; 江黄区第二、三产业分别增加 $8.1 \%$ 和 $9.6 \%$, 人均可支配收人和支出分别增加 $10.3 \%$ 和 $2.2 \%$ 。
对比各城乡融合区扩展情况发现,江夏区经济紧凑 度较高, 新洲区其次。市域内各区域的空间网络关 联是城市网络化内聚力形成的基础, 在一定程度上 能够反作用于城市圈层式扩张力, 抑制城市粗放增 长和效率低下问题, 提高城市发展紧凑度。

\section{2 城乡融合区空间关联测度}

借助 ArcGIS 的自然断点法将两两城乡融合区 间的空间关联强度分为 0 4、5 11、12 21、22 44 和 45 100 五个等级,并绘制城乡融合区间空间联系的 网络结构图(图4)。在样本年份内, 空间联系最初呈 现江夏区一武洪区一青山区的简单双线网络结构, 而后经过区域化扩散逐步发育成江夏区一武洪区 一江黄区一江硚东区一蔡汉区城乡融合区闭合环 状网络结构。具体而言, 2016年仅武洪区一江夏区 和武洪区一青山区城乡融合区联系量超过 22 , 其余 地区之间均未建立彼此间的紧密联系, 呈现出一定 程度的东西非均衡性; 武汉市城乡融合区的空间联 系呈现围绕武洪区的简单“V”型结构关系,空间联 (a) 2016年

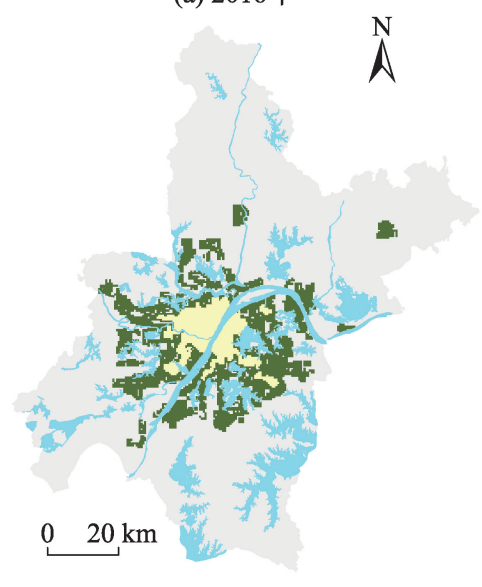

(b) 2017 年

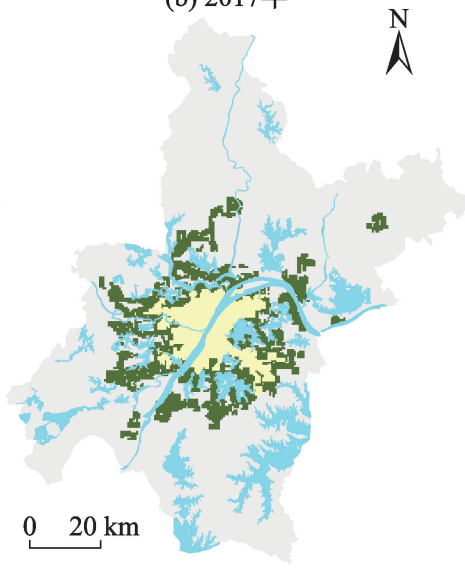

(c) 2018年

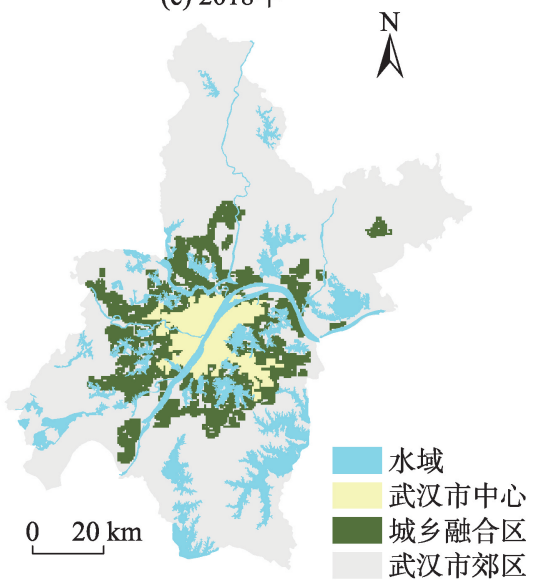

图 32016 -2018 年武汉市城乡融合区空间演变

Fig.3 Spatial pattern change of desakota regions in Wuhan City, 2016-2018

表 1 武汉市精明增长程度分析

Tab.1 Analysis of urban smart growth degree

\begin{tabular}{ccccccc}
\hline 行政区 & $\begin{array}{c}\text { 城乡融合区面积 } \\
\text { 增加值 } \%\end{array}$ & $\begin{array}{c}\text { 常住人口 } \\
\text { 增加值 } / \%\end{array}$ & $\begin{array}{c}\text { 第二产业 } \\
\text { 增加值/\% }\end{array}$ & $\begin{array}{c}\text { 第三产业 } \\
\text { 增加值/\% }\end{array}$ & $\begin{array}{c}\text { 人均可支配 } \\
\text { 收人增加值 } / \%\end{array}$ & $\begin{array}{c}\text { 人均消费 } \\
\text { 增加值 } / \%\end{array}$ \\
\hline 江硚东区 & 43.0 & 4.0 & 8.1 & 8.5 & 9.1 & 4.0 \\
蔡汉区 & 61.9 & 2.1 & 8.0 & 9.6 & 10.2 & 2.1 \\
江夏区 & 27.7 & 2.1 & 12.2 & 9.4 & 9.6 & 2.1 \\
江黄区 & 48.3 & 2.2 & 8.1 & 9.6 & 10.3 & 2.2 \\
新洲区 & 27.3 & 0.8 & 8.1 & 9.9 & 10.0 & 0.8 \\
\hline
\end{tabular}

注: 表中数据均为 2017 年相比 2016 年的增加值,数据来源于《2018 年武汉统计年鉴》; 由于汉阳区、青山区和武昌、洪山区的城乡融合区 面积比例相对较低,在此未对这 4 个行政区进行城乡融合区精明增长分析。 
(a) 2016年

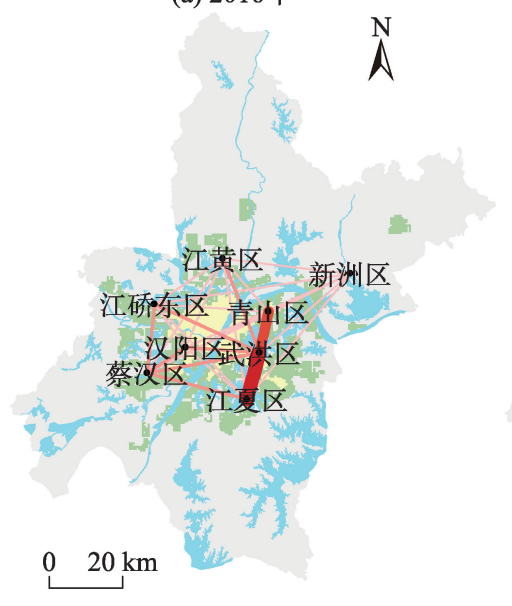

(b) 2017 年

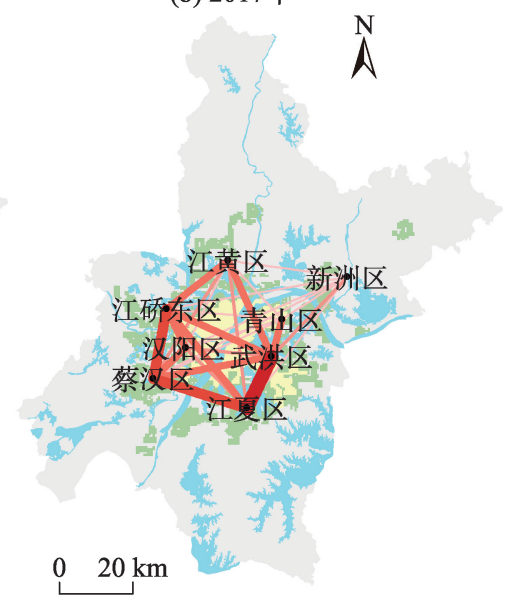

(c) 2018年

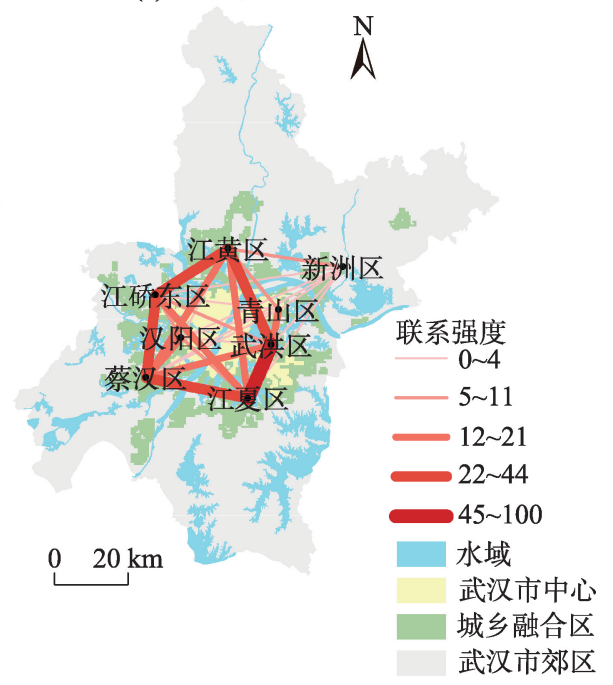

图4 2016-2018 年武汉城乡融合区空间联系强度变化

Fig.4 Change of spatial correlation intensity of desakota regions in Wuhan City, 2016-2018

系尚处于发展雉形阶段。2017年武洪区和青山区城 乡融合区联系量级有所减弱;武洪区和江夏区城乡 融合区联系量级不变,但开始扩散至邻接的蔡汉区 和江研东区,形成 “轴线式”联系, 其余城乡融合区 彼此间联系也开始加强。2018 年强联系关系从武 洪区和江夏区城乡融合区2个中心地区扩散至西北 部,城乡融合区间的空间联系量进一步增强, 逐渐 构成江夏区一武洪区一江黄区一江研东区一蔡汉 区城乡融合区闭合环状网络空间联系格局。总体 上看, 空间联系结构呈现 “多中心化” 变化趋势, 一 方面从武洪区单一联系中心 “V”型结构发展为多地 区闭合环式结构, 地区中心作用淡化; 另一方面早 期弱联系地区的空间联系级别上升, 这也同样淡化 了中心作用。

由上可知, 依据引力模型计算所得的各城乡融 合区空间引力强度, 江夏区和武洪区城乡融合区始 终居前 2 位, 且在 2016 年远高于其他地区。武洪区 和江夏区具有空间上的接近性,有利于基础设施建 设和产业经济的统一规划及协同发展。早在 1988 年武汉市江夏区和武洪区境内便创建了东湖新技 术开发区, 地理位置紧邻中心城区, 使两区的联合 发展具备地理优势、时间成本优势和资源优势; 区 内建设了汤逊湖大学科技园、光谷软件园、佛祖岭 产业园、关东光电子产业园、关南生物医药产业园、 机电产业园等多个园区, 众多高校及研究机构促使 东湖新技术开发区成为武洪区和江夏区城乡融合 区的社会、经济、人才、科技和信息关联纽带, 极大
地带动了 2 个区域的综合能力提升和空间关联加 强, 从而形成武洪区一江夏区城乡融合区两大发展 中心。蔡汉区、江研东区和江黄区城乡融合区之间 的空间强度在 2016-2018年逐年增强,缓解了武汉 市城乡融合区空间发展不均衡问题,但各区增强原 因因地而异。蔡甸经济开发区交通条件便捷、基础 设施完善且产业特色鲜明, 为蔡甸区城乡融合区发 展奠定了良好基础, 后来蔡甸区中法武汉生态示范 城的建设启动了大批大型公共设施、基础设施和生 态项目, 吸引大量人才、资源、信息和科技等支持蔡 甸区城乡融合区的建设发展, 也使生态示范城逐渐 成为武汉国际交往活动聚集地,进一步提升了蔡甸 区城乡融合区与其他区域的空间关联强度。黄陂 区境内高等级公路路网密度位居全省第 1 位, 且拥 有武汉天河国际机场、武汉新港和武汉北铁路编组 站 3 大国家级交通枢纽,逐步完善的公、水、空、铁立 体交通网络是其城乡融合区空间联系强度等级后 期提升的重要因素。东西湖区全域和黄陂南部地 区属武汉临空经济区,其核心区位于机场 $15 \mathrm{~km}$ 圈 层之内, 临空经济发展优势明显。东西湖区城乡融 合区适宜发展航空运输、物流、飞机维修保养等空 港产业, 承担了重要的贸易物流功能, 临空经济是 江研东区和江黄区城乡融合区空间联系加强的关 键所在。随着各个经济开发区的建设和发展, 各城 乡融合区的经济发展水平、城镇化发展规模和交通 通达性发生变化, 不同城乡融合区所发展的产业与 承担的功能逐渐成熟并形态各异, 能否与其他城乡 
融合区产生强空间联系的关键在于彼此之间的要 素匹配度,因此空间联系结构在演变过程中趋向于 均衡发展。

\section{3 城乡融合区空间联系势能变化}

空间联系势能能够衡量某个城乡融合区与其 他城乡融合区空间联系的总体作用强度, 其值越 大, 则该城乡融合区的中心性和中心地位越高, 空 间辐射力和吸引力越大。利用式(7)分别计算2016、 2017、2018 年武汉市各城乡融合区的空间联系势能 (表2)。由表2 可知, 武汉市城乡融合区空间联系整 体格局从武洪区和江夏区的双中心结构发展演变 为江夏区一武洪区一蔡汉区一江黄区一江研东区 轴线式结构。进一步分析发现,2016年武洪区和江 夏区城乡融合区的空间联系势能占比之和超过其 他所有地区总和, 达到 $67.90 \%$, 双中心结构明显, 其 余地区均未超过 8\%。2016-2017年, 江黄区、江研 东区、新洲区和蔡汉区城乡融合区空间联系势能增 长迅速, 最高达 $262.92 \%$, 而武洪区和江夏区城乡融 合区空间联系势能增长相对缓慢。2018 年武洪区 和江夏区城乡融合区占比之和继续下降至 $45.93 \%$, 江研东区、蔡汉区和江黄区占比增长至 $45.00 \%$, 其 余地区占比总和仍不足 $10 \%$, 与其他城乡融合区形 成明显 “断层”, 充分反映武汉市各城乡融合区发展 不平衡现象。总体上, 武洪区和江夏区城乡融合区 占比始终居前 2 位; 汉阳区和青山区占比在 20162018 年起伏不定, 主要因其地理位置紧邻城市中 心, 城镇化发展迅速, 城乡融合区社会经济吸引力 增强的同时伴随着面积的缩减, 导致城乡融合区的 关联强度发生相对变化; 新洲区因其地理位置较偏 僻、综合能力欠佳, 空间联系势能一直较低; 其他地 区的占比均逐步升高。武汉城乡融合区空间联系
的结构演化呈现一个基本特征: 从“大小中心”结构 (武洪区城乡融合区为大中心, 江夏区城乡融合区 为小中心)过渡到 “外围圈层式”结构(江夏区一武洪 区一蔡汉区一江黄区一江硚东区城乡融合区)。

根据武汉市城乡融合区空间联系势能计算 2016-2018 年各区社会经济区位度变化(图 5), 青 山区、武洪区、汉阳区和江夏区城乡融合区社会经 济区位度均有所下降, 新洲区、蔡汉区、江研东区和 江黄区城乡融合区区位度上升幅度依次增加, 说明 依托天河机场航空运输优势的北部新城组群发展 最为迅速, 以食品加工、现代物流和轻工产业为主 导的西部新城组群发展也较为突出, 而东部新城组 群的发展重要性呈逐渐落后趋势, 即现行武汉市都 市发展区规划实施成效在北部、西部和东北部城乡 融合区较为突出, 东部实施成效相对较小。对比 2016-2018 年各城乡融合区社会经济区位度变化 率与灯光强度值总和变化率发现, 二者在排序上差 别较小, 相关性较强。青山区、武洪区和汉阳区城 乡融合区灯光强度变化率均为负, 新洲区、蔡汉区、 江研东区和江黄区城乡融合区灯光强度变化率均 为正, 且在数值大小排列顺序上较为一致。江夏区 城乡融合区区位度在 2016-2018 年有所下降,而灯 光强度值总和却有所上升。通过分析江夏区综合 发展状况,本文认为这是因为江夏区和武洪区境内 的东湖新技术开发区发展较快,而在各地区空间关 联强度测算过程中将东湖新技术开发区分割开来， 导致测算结果存在一定误差。总体上来说, 各城乡 融合区的区位度变化率和灯光强度值总和变化率 较为一致, 利用灯光遥感影像和引力模型能够测算 武汉市城乡融合区空间关联程度和区域综合发展 情况, 为城市发展战略提供理论参考。

表 $22016-2018$ 年武汉市城乡融合区空间联系势能

Tab.2 Spatial connection potential of desakota regions in Wuhan City, 2016-2018

\begin{tabular}{|c|c|c|c|c|c|c|c|c|}
\hline \multirow{2}{*}{ 区域 } & \multicolumn{2}{|c|}{ 2016年 } & \multicolumn{3}{|c|}{ 2017年 } & \multicolumn{3}{|c|}{ 2018年 } \\
\hline & 势能 & 占比 $/ \%$ & 势能 & 占比/\% & 增长/\% & 势能 & 占比 $/ \%$ & 增长 $/ \%$ \\
\hline 汉阳区 & 22.54 & 5.36 & 43.64 & 6.53 & 93.65 & 33.04 & 4.05 & -24.28 \\
\hline 青山区 & 30.69 & 7.29 & 21.43 & 3.20 & -30.16 & 25.37 & 3.11 & 18.40 \\
\hline 武洪区 & 167.47 & 39.81 & 175.17 & 26.19 & 4.60 & 187.06 & 22.92 & 6.79 \\
\hline 江硚东区 & 26.53 & 6.31 & 93.51 & 13.98 & 252.41 & 102.49 & 12.56 & 9.60 \\
\hline 蔡汉区 & 32.59 & 7.75 & 94.46 & 14.12 & 189.84 & 139.74 & 17.12 & 47.94 \\
\hline 江夏区 & 118.15 & 28.09 & 160.27 & 23.96 & 35.65 & 187.74 & 23.01 & 17.14 \\
\hline 江黄区 & 17.54 & 4.17 & 63.66 & 9.52 & 262.92 & 125.05 & 15.32 & 96.43 \\
\hline 新洲区 & 5.16 & 1.23 & 16.63 & 2.49 & 222.68 & 15.51 & 1.90 & -6.75 \\
\hline
\end{tabular}

注: 势能没有量纲, 数值大小代表空间联系强度; 占比表示某一城乡融合区占当年全部城乡融合区空间联系量总和的比重。 


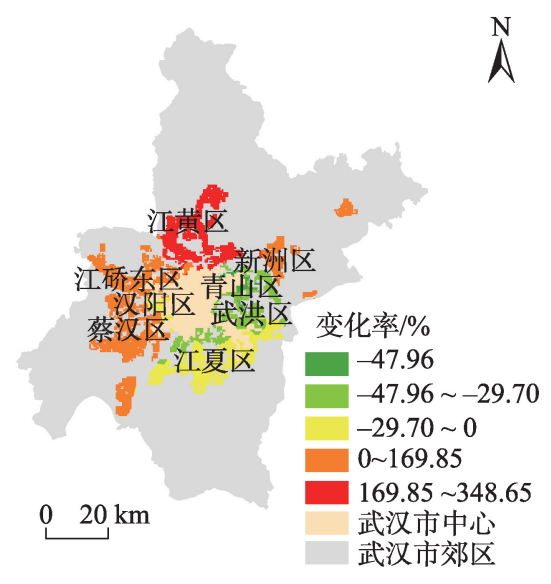

图 5 2016-2018年武汉市城乡融合区 经济社会区位度变化率

Fig.5 The rate of change of socioeconomic location index of desakota regions in Wuhan City, 2016-2018

\section{3 结论与政策建议}

\section{1 结论}

以武汉市城乡融合区为研究区域, 基于 NPP/ VIIRS 夜间灯光数据表征城乡融合区实时要素配置 及运行效率和效益, 通过引力模型测度各城乡融合 区间的空间关联, 获得空间联系势能及其时空演变 特征,量化了社会经济区位度变化。结果表明：

第一,城乡融合区面积变化意味着城市服务能 力及效益发挥边界向外扩张。武汉市城乡融合区 面积在 2016-2018 年间扩大了 $28.10 \%$, 小玟块区 域逐渐整合, 区域发展连续性增强; 城乡融合区总 体向西北方向扩展最为显著,蔡汉区、江黄区和新 洲区城乡融合区向外扩张最为明显; 对比武汉市各 行政区常住人口和经济增长情况, 江研东区在城镇 化发展过程中人口紧凑性较高, 江夏区经济紧凑性 较高。城市发展受圈层式扩张力和网络化内聚力 2 种作用力的共同影响, 圈层式扩张力是城镇化发展 的动力基础, 而网络化内聚力在一定程度上反向作 用于扩张趋势, 抑制圈层式扩张力带来的粗放增长 和效率低下问题, 提高城市发展紧凑度。

第二, 武汉市城乡融合区之间的空间联系网络 结构整体上趋向 “多中心”分布, 这一过程源于各城 乡融合区的经济发展水平、城镇化发展规模和交通 通达性变化。东湖新技术开发区、中法武汉生态示 范城、蔡甸经济开发区、武汉临空经济区等是各城乡 融合区的区域发展引擎, 随着各经济开发区的创建 与完善, 不同城乡融合区所发展的产业与承担的功
能逐渐成熟并形态各异, 能否与其他城乡融合区产 生强空间联系的关键在于彼此之间的功能互补性。

第三,武汉市城乡融合区空间联系强度整体上 逐年上升, 内部结构有所变化,但发展不均衡现象仍 明显。空间联系整体格局从武洪区和江夏区的“大 小中心”结构过渡到江夏区一武洪区一蔡汉区一江 黄区一江研东区的“外围圈层式”结构,表明武汉市 城乡融合区发展重心向西北方向偏移; 武洪区和江 夏区城乡融合区的空间联系势能占比从未低于全市 的 $45 \%$, 而新洲区城乡融合区空间势能始终不足 $6 \%$,武洪区和江夏区作为武汉市城乡融合区中心区 域, 未能形成多方向空间辐射力和吸引力, 对其他地 区的带动明显不足。各城乡融合区社会经济区位度 变化显示, 现行武汉市都市发展区规划实施成效在 北部、西部和东北部城乡融合区较为显著。

\section{2 政策建议}

第一,在武汉市新型城镇化背景下, 结合城乡 融合区发展“多中心”趋势, 各区域, 尤其是非中心 城乡融合区的发展机会越来越大, 功能也将逐渐凸 显。但介于先发优势和门槛的存在, 后发区域应注 重特色化发展,结合本区域产业特色和自然资源优 势走互补、错位发展道路。比如洪山区城乡融合区 可以侧重发展高新技术产业; 蔡甸区城乡融合区可 以侧重建设生态宜居新城; 黄陂区可以侧重发展商 贸物流建设。

第二, 要加强武汉市城乡融合区间的空间联系 强度,经济开发区是重要的区域发展引擎。政府相 关部门应分析武汉市整体和各区域各方面的发展 状况和条件, 找到有发展潜力的城乡融合区, 率先 投人创新资源, 采取优惠政策使其快速发展,鼓励 与周边地区发展横向多边关系, 促进多城乡融合区 共同发展。

第三,城乡融合区的高效、集约发展是城市高 质量发展的重要体现,在推进城镇化的同时,强化 各区位新增空间与存量空间相互之间的关联性研 究,有助于城市不同区域在人口、经济、土地利用结 构等方面紧凑布局, 以多方位实现城市精明增长。

\section{参考文献(References)}

[1] Mohammed I, Alshuwaikhat H M, Adenle Y A. An approach to assess the effectiveness of smart growth in achieving sustainable development [J]. Sustainability, 2016, 8(4): 397-418.

[2] 熊皓, 郑伯红, 贾磊. 驱动力与制约力相互作用下我国城 
市空间扩张 [J]. 经济地理, 2016, 36(1): 82-88. [Xiong Hao, Zheng Bohong, Jia Lei. Urban space expansion in China under the interaction between the driving force and the restriction. Economic Geography, 2016, 36(1): 82-88. ]

[3] 刘和涛, 田玲玲, 田野, 等. 武汉市城市曼延的空间特征 与管治 [J]. 经济地理, 2015, 35(4): 47-53. [Liu Hetao, Tian Lingling, Tian Ye, et al. Exploring the spatial expression and governance policies of urban sprawl in Wuhan. Economic Geography, 2015, 35(4): 47-53. ]

[4] 任启龙, 王利, 韩增林, 等. 基于城市年轮模型的城市扩 展研究: 以沈阳市为例 [J]. 地理研究, 2017, 36(7): 13641376. [Ren Qilong, Wang Li, Han Zenglin, et al. Research on urban expansion based on urban annual rings: A case study of Shenyang. Geographical Research, 2017, 36(7): 1364-1376. ]

[5] 秦蒙, 刘修岩, 李松林. 中国的“城市曼延之谜”: 来自政 府行为视角的空间面板数据分析 [J]. 经济学动态, 2016 (7): 21-33. [Qin Meng, Liu Xiuyan, Li Songlin. China's "mystery of urban spread": Spatial panel data analysis from the perspective of government behavior. Economic Perspectives, 2016(7): 21-33. ]

[6] 陈宝芬, 张耀民, 江东. 基于 CA-ABM 模型的福州城市用 地扩张研究 [J]. 地理科学进展, 2017, 36(5): 626-634. [Chen Baofen, Zhang Yaomin, Jiang Dong. Urban land expansion in Fuzhou City based on coupled cellular automata and agent-based models (CA-ABM). Progress in Geography, 2017, 36(5): 626-634. ]

[7] 熊昌盛, 谭荣, 岳文泽. 快速城市化背景下不同建设用地 扩张的驱动差异探讨: 以浙江省义乌市为例 [J]. 自然资 源学报, 2018, 33(12): 2124-2135. [Xiong Changsheng, Tan Rong, Yue Wenze. Discussion on different driving factors of diversified construction land expansion in rapid urbanization area: A case study of Yiwu City. Journal of Natural Resources, 2018, 33(12): 2124-2135. ]

[8] Han R B, Cao H H, Liu Z W. Studying the urban hierarchical pattern and spatial structure of China using a synthesized gravity model [J]. Science China: Earth Sciences, 2018, 61(12): 1818-1831.

[9] Li L Y, Sun Z X, Long X. An empirical analysis of nighttime light data based on the gravity model [J]. Applied Economics, 2019, 51(8): 797-814.

[10] Kuik O, Branger F, Quirion P. Competitive advantage in the renewable energy industry: Evidence from a gravity model [J]. Renewable Energy, 2019, 131: 472-481.

[11] Ye C D, Zhu Y S, Yang J X, et al. Spatial equity in accessing secondary education: Evidence from a gravity-based model [J]. The Canadian Geographer: Le Geographe Canadien, 2018, 62(4): 452-469.

[12] 王海军, 翟丽君, 刘艳芳, 等. 基于多维城市要素流的武 汉城市圈城市联系与功能分析 [J]. 经济地理, 2018, 38
(7): 50-58. [Wang Haijun, Zhai Lijun, Liu Yanfang, et al. Urban connection and function in Wuhan urban agglomeration based on multi- dimensional urban factor flows. Economic Geography, 2018, 38(7): 50-58. ]

[13] 许芸鹭, 雷国平. 辽中南城市群空间联系测度 [J]. 城市 问题, 2018(11): 65-74. [Xu Yunlu, Lei Guoping. Measure of spatial corelation of urban agglomeration in the middle and south of Liaoning Province. Urban Problems, 2018(11): 65-74. ]

[14] 葛浩然, 朱占峰, 钟昌标, 等.基于引力和客运联系的浙 江省城镇网络特征 [J]. 长江流域资源与环境, 2018, 27 (6): 1186-1197. [Ge Haoran, Zhu Zhanfeng, Zhong Changbiao, et al. Characteristics of urban network in zhejiang province based on gravity and passenger linkage. Resources and Environment in the Yangtze Basin, 2018, 27 (6): 1186-1197. ]

[15] 魏国恩, 朱翔, 贺清云. 环长株潭城市群空间联系演变 特征与对策研究 [J]. 长江流域资源与环境, 2018, 27 (9): 1958-1966. [Wei Guoen, Zhu Xiang, He Qingyun. Study on the evolution characteristics and countermeasures of spatial evolvement relation in urbanagglomeration around Changsha- Zhuzhou- Xiangtan. Resources and Environment in the Yangtze Basin, 2018, 27(9): 1958-1966. ]

[16] 刘玉, 冯健. 城乡结合部农业地域功能实现程度及变化 趋势: 以北京为例 [J]. 地理研究, 2017, 36(4): 673-683. [Liu Yu, Feng Jian. Analysis on execution and change of regional function of agriculture in rural-urban fringe: A case study of Beijing. Geographical Research, 2017, 36 (4): 673-683. ]

[17] Yang Y, Ma M, Tan C, et al. Spatial recognition of the urban-rural fringe of Beijing using DMSP/OLS nighttime light data [J]. Remote Sensing, 2017, 9(11): 13.

[18] 徐康宁, 陈丰龙, 刘修岩. 中国经济增长的真实性: 基于 全球夜间灯光数据的检验 [J]. 经济研究, 2015, 50(9): 17-29, 57. [Xu Kangning, Chen Fenglong, Liu Xiuyan. The Truth of China economic growth: Evidence from global night-time light data. Economic Research Journal, 2015, 50(9): 17-29, 57. ]

[19] Ma T, Yin Z, Zhou A. Delineating spatial patterns in human settlements using VIIRS nighttime light data: A watershed- based partition approach $[\mathrm{J}]$. Remote Sensing, 2018, 10(3): 465-478.

[20] 杨洋, 黄庆旭, 章立玲. 基于 DMSP/OLS 夜间灯光数据 的土地城镇化水平时空测度研究: 以环渤海地区为例 [J]. 经济地理, 2015, 35(2): 141-148, 168. [Yang Yang, Huang Qingxu, Zhang Liling. The spatial-temporal measurement on the land urbanization level using DMSP/ OLS nighttime light data: A case study of Bohai Rim. Economic Geography, 2015, 35(2): 141-148, 168. ] 
[21] Pan J, Hu Y. Spatial identification of multi-dimensional poverty in rural China: A perspective of nighttime-light remote sensing data $[\mathrm{J}]$. Journal of the Indian Society of Remote Sensing, 2018, 46(7): 1093-1111.

[22] 吴健生, 牛妍, 彭建, 等. 基于 DMSP/OLS 夜间灯光数据 的 1995-2009年中国地级市能源消费动态 [J]. 地理研 究, 2014, 33(4): 625-634. [Wu Jiansheng, Niu Yan, Peng Jian, et al. Research on energy consumption dynamic among prefecture-level cities in China based on DMSP/ OLS nighttime light. Geographical Research, 2014, 33 (4): 625-634. ]

[23] Donaldson D, Storeygard A. The view from above: Applications of satellite data in economics [J]. Journal of Economic Perspectives, 2016, 30(4): 171-198.

[24] 耿虹, 时二鹏, 王立舟, 等. 基于 GIS-DEA 的大城市周边 小城镇发展效率评价: 以武汉为例 [J]. 经济地理, 2018, 38(10): 72-79. [Geng Hong, Shi Erpeng, Wang Lizhou, et al. Evaluation of the development efficiency of small towns around metropolis based on gis-dea: Taking Wuhan as an example. Economic Geography, 2018, 38 (10): 72-79. ]

[25] 方创琳, 刘晓丽, 萄雪芹. 中国城市化发展阶段的修正 及规律性分析 [J]. 干旱区地理, 2008, 31(4): 512-523. [Fang Chuanglin, Liu Xiaoli, Lin Xueqin. Satges correciton and regulairty analysis of urbanization course of China. Arid Land Geography, 2008, 31(4): 512-523. ]

[26] Liao L B, Weiss S, Mills S, et al. Suomi NPP VIIRS daynight band on-orbit performance [J]. Journal of Geophysical Research-Atmospheres, 2013, 118(22): 12705-12718.

[27] Elvidge C D, Baugh K E, Zhizhin M et al. Why VIIRS data are superior to DMSP for mapping nighttime lights [J]. Proceedings of the Asia-Pacific Advanced Network, 2013, 35: 62-69.

[28] Li X, Zhou Y. Urban mapping using DMSP/OLS stable night-time light: A review [J]. International Journal of Remote Sensing, 2017, 38(21): 6030-6046.

[29] Dou Y, Liu Z, He C et al. Urban land extraction using VIIRS nighttime light data: An evaluation of three popular methods [J]. Remote Sensing, 2017, 9(2): 175-191.

[30] Yang Y, He C, Zhang Q, et al. Timely and accurate national-scale mapping of urban land in China using Defense Meteorological Satellite Program's Operational Linescan System nighttime stable light data [J]. Journal of Applied Remote Sensing, 2013, 7(1), doi: 10.1117/1. JRS.7.073535.

[31] 万银锋. 城镇化进程中城乡结合部的社会治理转型与 创新 [J]. 中州学刊, 2017(11): 14-18. [Wan Yinfeng. Social governance transition and innovation of urban-rural integration in the process of urbanization. Academic Journal of Zhongzhou, 2017(11): 14-18. ]
[32] 周小驰, 刘咏梅, 杨海娟. 西安市城市边缘区空间识别 与边界划分 [J]. 地球信息科学学报, 2017, 19(10): 1327-1335. [Zhou Xiaochi, Liu Yongmei, Yang Haijuan. Spatial recognition and boundary region division of urban fringe area in Xi'an City. Journal of Geo-information Science, 2017, 19(10): 1327-1335. ]

[33] 王媛, 姜博, 初楠臣, 等. 基于建设用地变化的城市边缘 区提取方法与扩张模式研究: 以哈尔滨市为例 [J]. 经 济地理, 2016, 36(5): 26-32. [Wang Yuan, Jiang Bo, Chu Nanchen, et al. Extraction method and expansion patterns of the urban fringe based on construction land change: A case in Harbin City. Economic Geography, 2016, 36(5): 26-32. ]

[34] 刘崇刚, 孙伟, 曹玉红, 等. 大都市区城乡空间边界演化 识别方法研究: 以南京市为例 [J]. 长江流域资源与环 境, 2018, 27(10): 2214-2221. [Liu Chonggang, Sun Wei, Cao Yuhong, et al. Identification method of urban-rural space boundary evolution in the metropolitan area: A case study of Nanjing. Resources and Environment in the Yangtze Basin, 2018, 27(10): 2214-2221. ]

[35] 张志刚, 张安明, 郭欢欢. 基于 DMSP/OLS 夜间灯光数 据的城乡结合部空间识别研究: 以重庆市主城区为例 [J]. 地理与地理信息科学, 2016, 32(6): 37-42. [Zhang Zhigang, Zhang Anming, Guo Huanhuan. Spatial recognition of the urban- rural fringe based on DMSP/OLS nighttime light data: A case study of the main urban areas of Chongqing. Geography and Geo-Information Science, 2016, 32(6): 37-42. ]

[36] 陈颖彪, 郑子豪, 吴志峰, 等. 夜间灯光遥感数据应用综 述和展望 [J]. 地理科学进展, 2019, 38(2): 205-223. [Chen Yingbiao, Zheng Zihao, Wu Zhifeng, et al. Review and prospect of application of nighttime light remote sensing data. Progress in Geography, 2019, 38(2): 205-223. ]

[37] 黄璐, 杨英宝, 朱琴. 基于 DMSP/OLS 数据的南京市建 成区扩展研究 [J]. 地理空间信息, 2018, 16(1): 94-97. [Huang Lu, Yang Yingbao, Zhu Qin. Expansion research on the build up area in Nanjing City based on DMSP/ OLS data. Geospatial Information, 2018, 16(1): 94-97. ]

[38] 刘继生, 陈彦光. 分形城市引力模型的一般形式和应用 方法: 关于城市体系空间作用的引力理论探讨 [J]. 地 理科学, 2000, 20(6): 528-533. [Liu Jisheng, Chen Yanguang. The gravitational models of franctal cities: Theoretical basis and applied methods. Science Geographica Sinica, 2000, 20(6): 528-533. ]

[39] 顾朝林, 庞海峰. 基于重力模型的中国城市体系空间联 系与层域划分 [J]. 地理研究, 2008, 27(1): 1-12. [Gu Chaolin, Pang Haifeng. Study on spatial relations of Chinese urban system: Gravity model approach. Geographical Research, 2008, 27(1): 1-12. ]

[40] 张荆荆. 城市间相互作用对城镇用地扩张的影响 [D]. 
武汉: 华中农业大学, 2014. [Zhang Jingjing. Impacts of urban spatial interation on the urban land expansion: A case study of Wuhan City circle. 2014. Wuhan, China: Hua Zhong Agricultural University, 2014. ]

[41] 焦鹏飞, 张凤荣, 李灿, 等. 基于引力模型的县域中心村 空间布局分析: 以山西省长治县为例 [J]. 资源科学, 2014, 36(1): 45-54. [Jiao Pengfei, Zhang Fengrong, Li Can, et al. The spatial organization of central villages in Changzhi County based on the gravity model. Resources Science, 2014, 36(1): 45-54. ]

[42] 欧向军, 薛丽萍, 顾雯娟. 江苏省县市经济联系的空间 特征 [J]. 经济地理, 2015, 35(8): 24-31. [Ou Xiangjun, Xue Liping, Gu Wenjuan. Characteristic in space economic contacts of cities and counties in Jiangsu Province. Economic Geography, 2015, 35(8): 24-31. ]

[43] Yu B, Shi K, Hu Y, et al. Poverty evaluation using NPP-
VIIRS nighttime light composite data at the county level in China [J]. IEEE Journal of Selected Topics in Applied Earth Observations and Remote Sensing, 2015, 8(3): 1217-1229.

[44] 蒋天颖, 谢敏, 刘刚. 基于引力模型的区域创新产出空 间联系研究: 以浙江省为例 [J]. 地理科学, 2014, 34 (11): 1320-1326. [Jiang Tianying, Xie Min, Liu Gang. Spatial linkage of regional innovation output based on gravity model: A case study in Zhejiang Province. Science Geographica Sinica, 2014, 34(11): 1320-1326. ]

[45] 陈昕, 彭建, 刘炎序, 等. 基于 DMSP/OLS 夜间灯光数据 的京津冀地区城市空间扩展与空间关联测度 [J]. 地理 研究, 2018, 37(5): 898-909. [Chen Xin, Peng Jian, Liu Yanxu, et al. Measuring spatial expansion and correlations of cities in Beijing-Tianjin-Hebei urban agglomeration. Geographical Research, 2018, 37(5): 898-909. ]

\title{
Spatial change and correlations of desakota regions in a metropolitan area using NPP/VIIRS nighttime light data: A case study of Wuhan City
}

\author{
WU Yan, LI Hongbo* \\ (College of Public Administration, Huazhong Agricultural University, Wuhan 430070, China)
}

\begin{abstract}
Research on the spatial-temporal change and intrinsic spatial correlation of metropolitan urban-rural integration zones can help cities to avoid inefficient sprawling development and achieve spatial structure coordination and smart growth. Taking the desakota region in Wuhan City as the case, we used the National Polar- Orbiting Partnership/ Visible Infrared Imaging Radiometer Suite (NPP/VIIRS) nighttime light data to assess urban factor allocation and operational efficiency and effectiveness. This study then detected the spatial correlation intensity, spatial-temporal change of spatial connection potential, and the change of socioeconomic location index of the urban-rural integration areas during 2016-2018 using the gravity model. The results show that: 1) The desakota regions in Wuhan City have expanded by $28.10 \%$, and sprawl most significantly to the northwest during 2016-2018. This process is characterized by the integration of small plaques and the enhancement of regional development continuity. 2) The spatial connection network structure among desakota regions in Wuhan tends to be polycentric, which originates from the changes of economic development levels, urbanization development scale, and traffic accessibility. Wuhan East Lake High-tech Development Zone, SinoFrench Wuhan Ecological Demonstration City, Wuhan Airport Economic Zone and so on are the engine of regional development in a decentralized process. 3) The spatial correlation pattern of urban-rural integration areas in Wuhan has been transformed from the "large and small cores" structure consisted of Wuhong District and Jiangxia District to the "peripheral circle" structure composed of Jiangxia-Wuhong-Caihan-JianghuangJiangqiaodong. The spatial connection intensities of desakoda regions have increased year by year, but Wuhong and Jiangxia Districts, as the core areas of Wuhan urban-rural integration area, failed to develop multi-directional spatial radiation and attractiveness, which led to insufficient positive effects to other areas. 4) The changes of socioeconomic location index of each urban-rural integration area show that the impact of existing Wuhan urban planning is more significant in the northern, western, and northeastern parts of urban-rural integration area.
\end{abstract}

Keywords: spatial correlation; gravity model; NPP/VIIRS nighttime light data; desakota region; Wuhan City 